\title{
HEART RATE, HEART RATE VARIABILITY, FAECAL GLUCOCORTICOID METABOLITES AND AVOIDANCE RESPONSE OF DAIRY COWS BEFORE AND AFTER CHANGEOVER TO AN AUTOMATIC MILKING SYSTEM
}

\author{
Viktor JURKOVICH $^{1 *}$, Fruzsina Luca KÉZÉR ${ }^{2,3}$, Ferenc RUFF $^{4}$, Mikolt BAKONY $^{1}$, \\ Margit KULCSÁR ${ }^{5}$ and Levente KOVÁCS ${ }^{2,3}$
}

${ }^{1}$ Department of Animal Hygiene, Herd Health and Veterinary Ethology, University of Veterinary Medicine, István utca 2, H-1078 Budapest, Hungary; ${ }^{2}$ MTA-SZIE Large Animal Clinical Research Group, Üllő Dóra-major, Hungary; ${ }^{3}$ Institute of Animal Husbandry, Faculty of Agricultural and Environmental Science, Szent István University, Gödöllö, Hungary; ${ }^{4}$ Department of Methodology, Hungarian Central Statistical Office, Budapest, Hungary; ${ }^{5}$ Department and Clinic of Reproduction, University of Veterinary Medicine, Budapest, Hungary

(Received 22 December 2016; accepted 4 April 2017)

The heart rate variability (HRV) parameters of dairy cows were monitored during parlour (PARL) and the later installed automatic (AMS) milking on a small-scale commercial dairy farm in Hungary. The aim of the study was to assess stress in relation to the type of milking and the frequency of human interaction. Parlour milking involved regular moving and crowding of the animals with frequent human interaction, which were much less frequent in automatic milking. The first phase of the study was conducted prior to the changeover $[\mathrm{n}=27]$ and the second two months afterwards $[n=19$ (of the cows from the first phase)]. Heart rate (HR) was recorded by the Polar RS800 CX recording system. HRV parameters indicative of sympathovagal balance were calculated for periods of lying and standing in the barn, waiting before milking and milking, respectively. Morning and evening faecal glucocorticoid concentrations were also measured. Fear of humans was tested by an avoidance distance test. Baseline HRV parameters showed no difference $(\mathrm{P}>0.05)$ between the two systems. In the periods before, during and after milking a higher sympathetic tone was detected in cows in the PARL phase. Mean faecal glucocorticoid concentrations were higher at the time of parlour milking. The avoidance distance did not differ between the two phases. The results suggest that automatic milking might be less stressful for cows than

*Corresponding author; E-mail: jurkovich.viktor@univet.hu; Phone: 0036 (1) 478-4242; Fax: 0036 (1) 478-4243

This is an open-access article distributed under the terms of the Creative Commons Attribution License, which permits unrestricted use, distribution, and reproduction in any medium for non-commercial purposes, provided the original author and source are credited. 
parlour milking, possibly due to the shorter duration of restraint after milking and the less frequent human interaction.

Key words: Animal welfare, dairy cow, heart rate variability, cortisol, automatic milking

Automatic milking systems (milking robot, AMS) were first installed in the early 1990s in the Netherlands, and are now used in more than 8,000 dairies worldwide (Jacobs and Siegford, 2012a). Compared to parlour milking, automatic systems have the inevitable advantage of voluntary milking; however, it takes time for the animals to get adapted to a newly installed automatic milking system. A novel environment and isolation from mates during the time of milking can cause stress in cows (Rushen et al., 2001; Svennersten-Sjaunja and Pettersen, 2008; Jacobs and Siegford, 2012a). The variability of time intervals between two consecutive heartbeats ( $\mathrm{R}-\mathrm{R}$ interval) is a reliable indicator of the changes in the parasympathetic tone (von Borell et al., 2007) related to the stress response (Porges, 2003). In farm animals, the parasympathetic branch of the autonomic nervous system plays a key role in regulating heart rate (HR) in response to stress (Hopster and Blokhuis, 1994). Reduced vagal tone was found in cows subjected to waiting after parlour milking with non-voluntary exit (Kovács et al., 2013) or during milking in a novel milking environment (Sutherland et al., 2012). Heart rate variability (HRV-) based studies investigating the stress load involved in milking have reported inconsistent results of either higher (Gygax et al., 2008), lower (Hopster et al., 2002) or similar (Hagen et al., 2005) sympathetic tone in cows milked in robotic units compared to conventional systems.

The adrenocortical responses to stress can be assessed on the basis of the concentration of cortisol metabolites in biological samples (Möstl and Palme, 2002; Cook, 2012). Potentially painful veterinary procedures such as disbudding or rectal examination induce increased cortisol secretion (Nakao et al., 1994; Stafford and Mellor, 2011). Rough handling also results in higher plasma cortisol concentrations (Bauer et al., 2012). The plasma cortisol concentration is also influenced by the time of day (Möstl and Palme, 2002), the procedure of blood sampling (Negrão et al., 2004) and non-aversive events (Manteca, 1998). A direct relationship between faecal glucocorticoid metabolites, blood cortisol, and adrenal activity has been demonstrated in dairy cattle (Morrow et al., 2002; Möstl and Palme, 2002).

The quality of handling during milking is also important, as fear of people can be a major source of stress (Rushen and de Pasillé, 2015). Based on the study of Windschnurer et al. (2008), the avoidance distance is a good indicator (with respect to high inter-observer reliability and repeatability) of the human-animal relationship. 
The aim of the present study was to compare the stress load of milking in a parlour system with frequent and sometimes aversive handling with that in an automatic milking system with significantly less human interaction.

\section{Materials and methods}

\section{Animals and husbandry}

The study was performed on a small-scale (80 lactating cows) commercial dairy farm in Hungary (GPS position: N 47.6926935, E 19.6080115) prior to and following a changeover in the milking system from a conventional herringbone milking parlour to a milking robot. In the first study period (March 2013), when the parlour milking system (PARL) was in operation, 27 clinically healthy Holstein-Friesian dairy cows [age $=4.8 \pm 1.6$ years, parity $=2.6 \pm 0.5$, days in milk $(\mathrm{DIM})=213.3 \pm 36.4$, body condition score $(\mathrm{BCS})=2.6 \pm 0.5$, milk yield $=23.1 \pm$ $9.9 \mathrm{~kg}$ ] without any clinical or lameness issues in the previous two months were examined. In the second part of the study (May 2013) the same animals were involved $(\mathrm{BCS}=3.1 \pm 0.5$, milk yield $=18.3 \pm 9.1)$ two months after the AMS had been installed. In the latter period, data from only 19 out of the 27 animals could be recorded. The data of the other eight animals deriving from the first study period were excluded from the analysis due to calving or being unable to adjust to robotic milking.

Parlour milking. The animals were kept in a free-stall barn bedded with rubber mats in two separated production groups (lower yielding and highyielding, 35-40 animals each). All the experimental cows were chosen from the low-producing group, being in the last trimester of lactation, to avoid any possible disturbing factors near the early lactation that may affect the HRV parameters. Total mixed ration (TMR) was fed twice a day and water was available ad libitum. The cows were milked twice a day (05:00 and 17:00 o'clock) in a $2 \times 5$ stall herringbone milking parlour. A single person was responsible for milking the cows, including moving them from and back to the barn. It was observed that the milker often used aversive handling methods (shouting and sometimes hitting) when forcing the animals to move faster. The animals usually spent a relatively long time (on average $25 \mathrm{~min}$ with the extremes of 1 and $53 \mathrm{~min}$ ) in the holding pen outside the milking parlour.

Automatic milking. The conventional milking parlour was changed to a 1stall milking robot (DeLaval VMS, DeLaval International AB, Tumba, Sweden). The groups and the area of the barn were united, but no other elements of the housing or the feeding regime were changed. Semi-forced cow traffic was in operation, which meant that cows entered the feeding area through a one-way gate, and from there - based on the time passed since the last milking - they could either reach the resting area or the waiting area of the milking unit through a selec- 
tion gate. After milking, cows returned to the feeding area, and re-entered the resting area through the selection gate. The cows spent a short time (1 to $15 \mathrm{~min}-$ utes) in the waiting area of the AMS.

\section{Recording and analysis of $H R$ and $H R V$}

Heart rate was recorded using a Polar RS800 CX recording system, including two adhesive electrodes and a Polar H3 transmitter (Polar Oy Kempele, Finland). During PARL, HR monitors were fitted on the animals after the morning milking (between 06:30 and 08:00 o'clock) and recordings lasted until returning from the evening milking (between 20:00 and 21:00 o'clock). During the AMS period, the electrodes were attached in the morning (between 06:30 and 08:00 o'clock) and removed after a 24-h recording session. The electrodes were positioned and fixed as described in our earlier studies (Kovács et al., 2013, 2014). The heart rate was recorded continuously after a 2-h acclimatisation period.

In parallel with the HR recordings, the starting and end points of undisturbed bouts of lying and standing in the barn (without feeding or ruminating) were recorded using a stopwatch, while the duration of waiting before milking and of the main phase of milking was determined from video recordings (Canon Legria HF M36, CANON, Japan).

HR and HRV parameters were calculated for the periods of (1) undisturbed lying and (2) standing in the barn, (3) the period of waiting in the holding pen/ waiting area before milking (PREMILK), and (4) the period from the start of udder preparation until exiting the milking parlour/milking unit (MILK). The R-R signal streams were analysed in 3-min time windows (Task Force of ESCNASPE, 1996). Longer data streams were subdivided into several segments. Taking into account the circadian variation in HR and HRV (Kovács et al., 2016), the data of one occasion of robotic milking per cow - which was closest in time to the time of milking in the parlour system - was included in the analysis. Taking into account the effects of physical activity (Frondelius et al., 2015; Kovács et al., 2015b), cardiac parameters calculated for the PREMILK and MILK periods were compared to those calculated for periods of undisturbed standing.

The Kubios HRV software (version 2.0, University of Kuopio, Finland) was used for HRV analysis (Tarvainen and Niskanen, 2008). Ectopic heartbeats and artefacts were corrected as described in an earlier study (Kovács et al., 2015a). For computing frequency-domain HRV, R-R intervals were subjected to Fast Fourier Transformation of power spectrum analysis (Akselrod et al., 1981). Spectral parameters included the normalised power of the high-frequency band (HF) and the LF/HF ratio [the ratio between the low frequency (LF) component and HF], the latter of which reflects on the sympathovagal balance. The recommendations of von Borell et al. (2007) were considered by setting the limits of the spectral components as follows: LF: $0.05-0.20 \mathrm{~Hz}$, HF: $0.20-0.58 \mathrm{~Hz}$. For 
graphical representation of the correlation between successive $\mathrm{R}-\mathrm{R}$ intervals, where each interval in the time series $(\mathrm{RRi}+1)$ is plotted against its successor (RRi), the Poincaré plot was used. We calculated the standard deviation 1 (SD1), which strongly reflects vagal tone, and the sympathetic measure SD2/SD1 (the ratio between standard deviation 2 and SD1) as described in earlier reviews on humans (Task Force of ESC-NASPE, 1996) and on farm animals (von Borell et al., 2007).

\section{Analysis of faecal samples}

Faecal samples were collected twice a day for the analysis of cortisol metabolites (Möstl and Palme, 2002). About 50 to $100 \mathrm{~g}$ of faeces was obtained manually from the rectum once in the morning (immediately after fixing the HR monitors, between 06:30 and 08:30 o'clock) and once in the evening (in PARL: before removing the heart rate monitors, between 20:00 and 21:00 o'clock; in AMS: in the same time period, when animals were standing in the barn). Samples were stored on ice and frozen at $-18{ }^{\circ} \mathrm{C}$ within $2 \mathrm{~h}$ after collection until analysis, as described by Möstl et al. (2002). For the extraction of the faecal glucocorticoid metabolites, samples were thawed at room temperature, stirred, and $0.5 \mathrm{~g}$ of faeces was dispersed in $5 \mathrm{ml}$ of $80 \%$ methanol (Palme and Möstl, 1997). The dispersion was vortexed for $30 \mathrm{~min}$ and centrifuged at $+4{ }^{\circ} \mathrm{C}$ at $3000 \mathrm{rpm}$ for 20 min (Möstl et al., 2002). The supernatant was transferred into 1.5-ml Eppendorf tubes and stored at $-18{ }^{\circ} \mathrm{C}$ until further analysis. A H3 homemade radioimmunoassay was carried out to determine the concentration of faecal glucocorticoid metabolites following the description of Csernus (1982). All samples were analyzed in duplicate. Intra-assay and inter-assay coefficients of variation were calculated.

\section{Avoidance distance}

Fear of humans was tested by an avoidance distance test according to the Welfare Quality protocol (Welfare Quality, 2009). At the feed bunk, the animals were approached at a speed of one step per sec and a step length of approximately $60 \mathrm{~cm}$ with the arm held overhand in an angle of approximately $45^{\circ}$ from the body, until the animals showed signs of withdrawal or until touching the muzzle. We defined withdrawal when the animal moved back, turned their head to the side, or pulled back their head trying to get out of the feeding rack. In case of withdrawal the avoidance distance was estimated (the distance between the hand and the muzzle at the moment of withdrawal) with a resolution of $10 \mathrm{~cm}$ (200 to $10 \mathrm{~cm}$ possible). If withdrawal took place at a distance less than $10 \mathrm{~cm}$, the test result was still $10 \mathrm{~cm}$. If the muzzle could be touched, an avoidance distance of $0 \mathrm{~cm}$ was recorded. Animals were retested $30 \mathrm{~min}$ later and the average of the two measurements were used for statistical analysis. 


\section{Statistical analysis}

All statistical analyses were performed in the R-3.0.2 statistical environment (R Core Team, 2015). For reducing the number of statistical comparisons between PARL and AMS, cardiac response parameters were calculated as area under the curve (AUC), which represents both the magnitude of the response and the changes occurring over time (Fekedulegn et al., 2007). Areas under the response curves were determined for each individual in the PREMILK and MILK periods utilising a trapezoid method described by Lay et al. (1996) as follows:

$\mathrm{AUC}=\Sigma[(\mathrm{Pn}+\mathrm{Pn}+1) / 2 \times \mathrm{m}-\mathrm{BASELINE}]$,

where ' $\mathrm{P}$ ' is the HRV parameter at a given time point, ' $\mathrm{m}$ ' is the time in minutes between the two P values and 'baseline' is the mean value of recorded HR and HRV measures during the undisturbed standing position in the barn, before milking.

The data were then tested for constant variance (modified robust BrownForsythe Levene-type test) and the Shapiro-Wilk test was used for testing normality of data for both PARL and AMS periods. For the comparison of cardiac autonomic responses between the PARL and AMS periods, the Friedman rank sum test were used. Comparisons between the PARL and AMS periods for faecal cortisol, avoidance distance as well as HR and HRV parameters calculated for lying and standing were made by the paired $t$-test (for data of normal distribution) and the Wilcoxon non-parametric test (in case of non-normal distribution). The level of significance was set at 0.05 in all cases.

\section{Results}

Baseline HR and HRV parameters - calculated for lying and standing showed no differences when comparing the two systems (Table 1).

In the PREMILK period, the AUC of HR, SD1/SD2 and LF/HF were higher, while the AUC of HF was lower in PARL compared to AMS, indicating a higher sympathetic tone in parlour milking (Table 2). Comparing the MILK period, the HR did not differ between PARL and AMS; however, the AUC values of SD2/SD1 and LF/HF were higher, while HF was lower in case of parlour milking, again indicating a higher sympathetic tone.

Concentrations of faecal corticosteroids were significantly higher during the parlour milking period, both in the morning and in the evening samples (Table 3).

We found no difference in the avoidance distance between the study periods $(\mathrm{PARL}=23.4 \pm 5.7 \mathrm{~cm} ; \mathrm{AMS}=37.1 \pm 9.7 \mathrm{~cm} ; \mathrm{P}=0.204)$. 
Table 1

Heart rate and heart rate variability parameters measured in the barn, during lying and standing ${ }^{1}$

\begin{tabular}{|c|c|c|c|c|c|c|c|}
\hline \multirow{2}{*}{ Item $^{2}$} & \multirow{2}{*}{$\begin{array}{l}\text { Indicative of } \\
\text { sympathetic/ } \\
\text { vagal tone }\end{array}$} & \multicolumn{3}{|c|}{ Lying } & \multicolumn{3}{|c|}{ Standing } \\
\hline & & $\mathrm{PARL}^{3}$ & $\mathrm{AMS}^{4}$ & $\mathrm{P}$ value & PARL & AMS & $\mathrm{P}$ value \\
\hline $\operatorname{HR}\left(\min ^{-1}\right)$ & & $66.2 \pm 1.0$ & $66.2 \pm 1.1$ & 0.997 & $78.1 \pm 3.5$ & $71.0 \pm 1.3$ & 0.335 \\
\hline HF (n.u.) & Vagal tone & $46.1 \pm 2.5$ & $49.7 \pm 2.5$ & 0.387 & $24.8 \pm 4.6$ & $18.6 \pm 2.5$ & 1.000 \\
\hline $\mathrm{LF} / \mathrm{HF}$ & $\begin{array}{l}\text { Symp./ } \\
\text { parasymp. } \\
\text { balance }\end{array}$ & $1.9 \pm 0.5$ & $1.4 \pm 0.2$ & 0.952 & $5.6 \pm 0.9$ & $7.7 \pm 1.5$ & 0.593 \\
\hline SD1 (ms) & Vagal tone & $16.4 \pm 1.8$ & $14.5 \pm 1.5$ & 0.349 & $13.9 \pm 6.1$ & $9.2 \pm 1.1$ & 0.108 \\
\hline $\mathrm{SD} 2 / \mathrm{SD} 1$ & Symp. tone & $2.9 \pm 0.4$ & $3.4 \pm 1.2$ & 0.324 & $6.2 \pm 0.9$ & $6.6 \pm 0.6$ & 0.660 \\
\hline
\end{tabular}

${ }^{1}$ Descriptive statistics are based on means \pm SEM of non-transformed data; ${ }^{2} \mathrm{HR}=$ heart rate (beats/min); $\mathrm{HF}=$ the high-frequency component [where n.u. = normalised units); $\mathrm{SD} 1=$ standard deviation of instantaneous $\mathrm{R}-\mathrm{R}$ variability measured from axis 1 in the Poincaré plot; SD2/SD1 = the ratio between SD2 (standard deviation of long-term continuous $\mathrm{R}-\mathrm{R}$ variability measured from axis 2 in the Poincare plot) and SD1; ${ }^{3} \mathrm{PARL}=$ the period of conventional milking; ${ }^{4} \mathrm{AMS}=$ the period of automatic milking system

Table 2

Areas under the curves (AUC) for heart rate and heart rate variability parameters calculated for premilking and milking periods ${ }^{1}$

\begin{tabular}{|c|c|c|c|c|c|c|c|}
\hline \multirow{2}{*}{ Item $^{2}$} & \multirow{2}{*}{$\begin{array}{l}\text { Indicative of } \\
\text { sympathetic/ } \\
\text { vagal tone }\end{array}$} & \multicolumn{3}{|c|}{ Lying } & \multicolumn{3}{|c|}{ Standing } \\
\hline & & PARL $^{3}$ & $\mathrm{AMS}^{4}$ & $P$ value & PARL & AMS & $P$ value \\
\hline $\operatorname{HR}\left(\min ^{-1}\right)$ & & $66.2 \pm 1.0$ & $66.2 \pm 1.1$ & 0.997 & $78.1 \pm 3.5$ & $71.0 \pm 1.3$ & 0.335 \\
\hline HF (n.u.) & Vagal tone & $46.1 \pm 2.5$ & $49.7 \pm 2.5$ & 0.387 & $24.8 \pm 4.6$ & $18.6 \pm 2.5$ & 1.000 \\
\hline LF/HF & $\begin{array}{l}\text { Symp./ } \\
\text { parasymp. } \\
\text { balance }\end{array}$ & $1.9 \pm 0.5$ & $1.4 \pm 0.2$ & 0.952 & $5.6 \pm 0.9$ & $7.7 \pm 1.5$ & 0.593 \\
\hline SD1 (ms) & Vagal tone & $16.4 \pm 1.8$ & $14.5 \pm 1.5$ & 0.349 & $13.9 \pm 6.1$ & $9.2 \pm 1.1$ & 0.108 \\
\hline SD2/SD1 & Symp. tone & $2.9 \pm 0.4$ & $3.4 \pm 1.2$ & 0.324 & $6.2 \pm 0.9$ & $6.6 \pm 0.6$ & 0.660 \\
\hline
\end{tabular}

${ }^{1}$ Descriptive statistics are based on means \pm SEM of non-transformed data; ${ }^{2} \mathrm{HR}=$ heart rate (beats/min); HF = the high-frequency component [where n.u. = normalised units); SD1 = standard deviation of instantaneous $\mathrm{R}-\mathrm{R}$ variability measured from axis 1 in the Poincaré plot; SD2/SD1 = the ratio between SD2 (standard deviation of long-term continuous $\mathrm{R}-\mathrm{R}$ variability measured from axis 2 in the Poincaré plot) and SD1; ${ }^{3} \mathrm{PARL}=$ the period of conventional milking; ${ }^{4} \mathrm{AMS}=$ the period of automatic milking system 
Table 3

Faecal corticosteroid concentrations during the study periods ${ }^{1}$

\begin{tabular}{lcc}
\hline \multirow{2}{*}{ Study period $^{2}$} & \multicolumn{2}{c}{ Corticosteroid concentrations (ng/g) } \\
\cline { 2 - 3 } & Morning & Evening \\
\hline PARL & $54.5 \pm 3.1^{\mathrm{a}}$ & $58.2 \pm 4.3^{\mathrm{A}}$ \\
AMS & $20.6 \pm 1.8^{\mathrm{b}}$ & $19.0 \pm 1.9^{\mathrm{B}}$ \\
\hline
\end{tabular}

${ }^{1}$ Descriptive statistics are based on means \pm SEM of nontransformed data. Different superscripts in the same column refer to significant differences between cortisol levels $\left({ }^{\mathrm{a}, \mathrm{b}} \mathrm{P}<0.05,{ }^{\mathrm{A}, \mathrm{B}} \mathrm{P}<0.01\right) ;{ }^{2} \mathrm{PARL}=$ the period of conventional milking, $\mathrm{AMS}=$ the period of automatic milking system

\section{Discussion}

In this study, we have compared the cardiac parameters, faecal glucocorticoid concentrations and avoidance distance of cows milked in a parlour and frequently experiencing aversive handling (shouting and sometimes hitting during moving them to the milking parlour), to that of the same cows two months after parlour milking had been changed to a milking robot and human interaction had become less frequent. The handling method during PARL was the way the milker handled the animals, it was not an experimental condition. Although Hopster et al. (2002) studied the effects of AMS 4 weeks after the changeover, we have found that an 8-week interval is more appropriate to exclude not only the effects of transition to the new milking system (Weiss et al., 2004, 2005; Jacobs and Siegford, 2012b) but also the possible long-term effects of rough handling. Considering that cows can remember the site of the preferred feed for at least 6 weeks (Kovalčik and Kovalčik, 1986) and positive handling had prolonged effects on the avoidance reaction for 8 weeks (Schmied et al., 2008), we supposed that unpleasant experiences might as well have a longer-term influence on behaviour. Physical activity, space allowance, milking frequency, parity and milk yield have a considerable impact on HRV (Kovács et al., 2015b). None of these factors changed significantly between the first and the second study period. The experimental animals were in mid- and late lactation and the difference in milk yield between the study periods was not significant $(P=0.132)$. Metabolic disorders that might influence behaviour or the level of stress are rare in this period of the lactation (Ingvartsen et al., 2003; Brydl et al., 2015). Season has only moderate importance in the interpretation of HRV parameters (Kovács et al., 2015b). Pregnancy-related weight gain in the given period is not as intensive as in the dry period and the body condition scores of the experimental animals did not differ significantly $(\mathrm{P}=0.08)$. 
Baseline HR and HRV parameters calculated for lying and standing did not differ between the two milking systems. Earlier studies found elevated (Gygax et al., 2008) or similar (Hagen et al., 2005) HR during lying posture in AMS compared to conventional milking systems; however, both studies reported on higher basal sympathetic tone in AMS. Hopster et al. (2002) found no difference between HR and HRV measured during standing in the barn in either parlour or robotic milking systems. We suppose that stress related to the procedure of milking in the conventional system is acute, considering that between two milkings the cows are left undisturbed in the barn, without human presence, free to rest or perform their daily activities, just as in the robotic milking system.

In the period of PREMILK, there were significant differences between the two systems regarding all parameters. AUCs calculated for HR, frequency domain and Poincaré measures of HRV indicated lower vagal and higher sympathetic activity in parlour milking. Hopster et al. (2002) also reported lower HR in the waiting area in AMS, compared to PARL. Stress was presumably a result of aversive handling methods (Pajor et al., 2000) or crowding in the holding area (Morgan and Tromborg, 2007; Kovács et al., 2013).

During the MILK period, HRV parameters reflected lower vagal tone and higher sympathetic activity in cows in PARL compared to AMS. Waiting for exiting the milking stall after the milking has finished is stressful for cows (Kovács et al., 2013). In PARL, it took an inevitably longer time (4.8 $\pm 1.0 \mathrm{~min})$, due to the individual differences in milk let-down speed, compared to AMS, where it was considerably shorter $(0.3 \pm 0.15 \mathrm{~min})$.

Earlier results investigating the changes of $\mathrm{HR}$ and HRV during milking in AMS or PARL are inconsistent. Gygax et al. (2008) reported an increased stress level (higher HR and lower vagal tone) in AMS, Hopster et al. (2002) found lower HR and adrenaline levels in AMS, whereas Hagen et al. (2005) found no difference in HR and HRV between AMS and PARL. Their results suggest that there are multiple factors that can influence the level of stress experienced during milking, which are needed to be identified and compared in further stress assessment studies. Considering that in the present study the basal HRV parameters did not differ between the two study periods, the changes in HRV measured during PREMILK and MILK must have arisen from differences in the milking system and in the way of handling.

Faecal cortisol concentrations determined twice a day adequately represent the level of stress experienced in the preceding $24 \mathrm{~h}$ (Möstl and Palme, 2002). In the present study, faecal cortisol concentrations were higher in the period of PARL than in AMS. Others have found no difference in cortisol concentrations measured in plasma (Hopster et al., 2002; Abeni et al., 2005), milk (Gygax et al., 2006) or faeces (Hopster et al., 2002). Considering that basal HRV parameters did not differ between the two study periods, the increase in hypothalamicpituitary-adrenal (HPA) activity in PARL can be linked to the effects of human 
interaction (Bauer et al., 2012) or the differences in the type of milking (Gorewit et al., 1992).

The avoidance distance did not differ in PARL and AMS in our study. The cows seem to remember and avoid those stockpersons who have treated them roughly (Munksgaard et al., 1997, 2001), and it was shown that the avoidance distance increases on farms where rough handling is frequent (Waiblinger et al., 2003; Rushen and de Pasillé., 2015). Cows can distinguish people and seem to generalise previous experience, especially if the people working around them wear clothing of the same colour (Munksgaard et al., 1997, 2001). In our study, the milker was not present at the time of the avoidance distance testing, and the persons performing the test were unfamiliar to cows and wore clothing that differed from that of the farm workers. The avoidance distance was relatively short in both the PARL and AMS periods. Two explanations may be assumed: (1) The negative experiences during handling the animals in relation to milking had not been generalised to other situations. (2) The type of avoidance distance testing was not sensitive enough to measure fine differences between the same animals at two time points, especially if we hope for an improvement of already small values. A slightly different approach (MacKay et al., 2014) may be more sensitive in such situations. Nevertheless, it is not common that farms employ only a single person for all the tasks involved in milking, including the herding of the animals.

\section{Conclusions}

In this study, parlour milking caused greater stress in dairy cows than robotic milking. The difference between conventional and automatic milking primarily arises from the duration of restraint after milking and the frequency and quality of animal handling. Increasing our knowledge on the nature of stressors involved in the process of milking - e.g. the quality of the milking routine, the attitude of milkers, the effects of isolation from herdmates, novelty in the environment, etc. - would help identify the most critical elements of parlour milking and improve animal welfare in conventional milking systems.

\section{Acknowledgements}

The study and the publication was supported by the Hungarian Ministry of $\mathrm{Hu}-$ man Resources (grant no.: 9878-3/2015/FEKUT, 9878-3/2016/FEKUT and 11475-4/2016/ FEKUT). 


\section{References}

Abeni, F., Calamari, L., Calza, F., Speroni, M., Bertoni, G. and Pirlo, G. (2005): Welfare assessment based on metabolic and endocrine aspects in primiparous cows milked in a parlor or with an automatic milking system. J. Dairy Sci. 88, 3542-3552.

Akselrod, S., Gordon, D., Ubel, F. A., Shannon, D. C., Berger, A. C. and Cohen, R. J. (1981): Power spectrum analysis of heart rate fluctuation: a quantitative probe of beat-to-beat cardiovascular control. Science 213, 220-222.

Bauer, J. M., Kegley, E. B., Richeson, J. T., Galloway, D. L., Hornsby, J. A. and Reynolds, J. L. (2012): Impact of different handling styles (good vs. adverse) on growth performance, behavior, and cortisol concentrations in beef cattle. Discovery 13, 3-10.

von Borell, E., Langbein, J., Després, G., Hansen, S., Leterrier, C., Marchant-Forde, J., Minero, M., Mohr, E., Prunier, A. and Veissier, I. (2007): Heart rate variability as a measure of autonomic regulation of cardiac activity for assessing stress and welfare in farm animals: a review. Physiol. Behav. 92, 293-316.

Brydl, E., Jurkovich, V., Tirián, A., Kovács, P. and Könyves, L. (2015): Incidence rate of subclinical metabolic disorders in Hungarian dairy herds during the last two decades [in Hungarian, with English abstract]. Magy. Allatorvosok 137, Suppl 1, 280-290.

Cook, N. J. (2012): Minimally invasive sampling media and the measurement of corticosteroids as biomarkers of stress in animals. Can. J. Anim. Sci. 92, 227-259.

Csernus, V. (1982): Antibodies of high affinity and specificity for RIA determination of progesterone, testosterone, estradiol-17b and cortisol. In: Görög, S. (ed) Advances in Steroid Analysis. Akadémiai Kiadó, Budapest, Hungary. pp 171-177.

Fekedulegn, D. B., Andrew, M. E., Burchfiel, C. M., Violanti, J. M., Hartley, T. A., Charles, L. E. and Miller, D. B. (2007): Area under the curve and other summary indicators of repeated waking cortisol measurements. Psychosom. Med. 69, 651-659.

Frondelius, L., Järvenranta, K., Koponen, T. and Mononen, J. (2015): The effects of body posture and temperament on heart rate variability in dairy cows. Physiol. Behav. 139, 437-441.

Gorewit, R. C., Svennersten, K., Butler, W. R. and Uvnäs-Moberg, K. (1992): Endocrine responses in cows milked by hand and machine. J. Dairy Sci. 75, 443-448.

Gygax, L., Neuffer, I., Kaufmann, C., Hauser, R. and Wechsler, B. (2006): Milk cortisol concentration in automatic milking systems compared with auto-tandem milking parlors. J. Dairy Sci. 89, 3447-3454.

Gygax, L., Neuffer, I., Kaufmann, C., Hauser, R. and Wechsler, B. (2008): Restlessness behaviour, heart rate and heart-rate variability of dairy cows milked in two types of automatic milking systems and auto-tandem milking parlours. Appl. Anim. Behav. Sci. 109, 167-179.

Hagen, K., Langbein, J., Schmied, C., Lexer, D. and Waiblinger, S. (2005): Heart rate variability in dairy cows - influences of breed and milking system. Physiol. Behav. 85, 195-204.

Hopster, H. and Blokhuis, H. J. (1994): Validation of a heart-rate monitor for measuring a stressresponse in dairy cows. Can. J. Anim Sci. 74, 465-474.

Hopster, H., Bruckmaier, R. M., van der Werf, J. T. N., Korte, S. M., Macuhova, J., Korte-Bouws, G. and van Renen, C. G. (2002): Stress responses during milking; comparing conventional and automatic milking in primiparous dairy cows. J. Dairy Sci. 85, 3206-3216.

Ingvartsen, K. L., Dewhurst, R. J. and Friggens, N. C. (2003): On the relationship between lactational performance and health: is it yield or metabolic imbalance that cause production diseases in dairy cattle? A position paper. Livest. Prod. Sci. 83, 277-308.

Jacobs, J. A. and Siegford, J. M. (2012a): The impact of automatic milking systems on dairy cow management, behavior, health and welfare. J. Dairy Sci. 95, 2227-2247.

Jacobs, J. A. and Siegford, J. M. (2012b): Lactating dairy cows adapt quickly to being milked by an automatic milking system. J. Dairy Sci. 95, 1575-1584. 
Kovács, L., Bakony, M., Tözsér, J. and Jurkovich, V. (2013): Changes in heart rate variability of dairy cows during conventional milking with nonvoluntary exit. J. Dairy Sci. 96, 7743-7747.

Kovács, L., Kézér, F. L., Bakony, M., Hufnagel, L., Tőzsér, J. and Jurkovich, V. (2015b): Associations between heart rate variability parameters and housing- and individual-related variables in dairy cows using canonical correspondence analysis. PLoS ONE 10, e0145313.

Kovács, L., Kézér, F. L., Jurkovich, V., Kulcsár-Huszenicza, M. and Tőzsér, J. (2015a): Heart rate variability as an indicator of chronic stress caused by lameness in dairy cows. PLoS ONE 10, e0134792.

Kovács, L., Kézér, F. L., Ruff, F. and Szenci, O. (2016): Cardiac autonomic activity has a circadian rhythm in summer but not in winter in non-lactating pregnant dairy cows. Physiol. Behav. $155,56-65$.

Kovács, L., Tőzsér, J., Szenci, O., Póti, P., Kézér, F. L., Ruff, F., Gábriel-Tőzsér, Gy., Hoffmann, D., Bakony, M. and Jurkovich, V. (2014): Cardiac responses to palpation per rectum in lactating and nonlactating dairy cows. J. Dairy Sci. 97, 6955-6963.

Kovalčik, K. and Kovalčik, M. (1986): Learning ability and memory testing in cattle of different ages. Appl. Anim. Behav. Sci. 15, 27-29.

Lay, D. C., Friend, T. H., Randel, R. D., Jenkins, O. C., Neuendorff, D. A., Kapp, G. M. and Bushong, D. M. (1996): Adrenocorticotropic hormone dose response and some physiological effects of transportation on pregnant Brahman cattle. J. Anim. Sci. 74, 1806-1811.

Manteca, X. (1998): Neurophysiology and assessment of welfare. Meat Sci. 49, Suppl. 1, S205S218.

MacKay, J. R., Haskell, M. J., Deag, J. M. and van Reenen, K. (2014): Fear responses to novelty in testing environments are related to day-to-day activity in the home environment in dairy cattle. Appl. Anim. Behav. Sci. 152, 7-16.

Morgan, K. N. and Tromborg, C. T. (2007): Sources of stress in captivity. Appl. Anim. Behav. Sci. 102, 262-302.

Morrow, C. J., Klover, E. S., Verkerk, G. A. and Mathews, L. R. (2002): Fecal glucocorticoid metabolites as a measure of adrenal activity in dairy cattle. Gen. Comp. Endocrinol. 126, 229-241.

Möstl, E. and Palme, R. (2002): Hormones as indicators of stress. Domest. Anim. Endocrinol. 23, $67-74$.

Möstl, E., Maggs, J. L., Schrötter, G., Besenfelder, U. and Palme, R. (2002): Measurement of cortisol metabolites in faeces of ruminants. Vet. Res. Comm. 26, 127-139.

Munksgaard, L., de Pasille, A. M., Rushen, J., Thodberg, K. and Jensen, M. B. (1997): Discrimination of people by dairy cows based on handling. J. Dairy Sci. 80, 1106-1112.

Munksgaard, L., de Passillé, A. M., Rushen, J., Herskin, M. S. and Kristensen, A. M. (2001): Dairy cows' fear of people: social learning, milk yield and behaviour at milking. Appl. Anim. Behav. Sci. 73, 15-26.

Nakao, T., Sayo, T., Moriyoshi, M. and Kawata, K. (1994): Plasma cortisol response in dairy cows to vaginoscopy, genital palpation per rectum and artificial insemination. Zbl. Vet-med. A 41, 16-21.

Negrão, J. A., Porcionato, M. A., de Passille, A. M. and Rushen, J. (2004): Cortisol in saliva and plasma of cattle after ACTH administration and milking. J. Dairy Sci. 87, 1713-1718.

Pajor, E. A., Rushen, J. and de Passillé, A. M. (2000): Aversion learning techniques to evaluate dairy cattle handling practices. Appl. Anim. Behav. Sci. 69, 89-102.

Palme, R. and Möstl, E. (1997): Measurement of cortisol metabolites in faeces of sheep as a parameter of cortisol concentration in blood. Int. J. Mammal. Biol. 62, 192-197.

Porges, S. W. (2003) The polyvagal theory: phylogenetic contributions to social behavior. Physiol. Behav. 79, 503-513.

R Core Team (2015): R: A Language and Environment for Statistical Computing. R Foundation for Statistical Computing, Vienna, Austria. URL: https://www.R-project.org/. 
Rushen, J. and de Passillé, A. M. (2015): The importance of good stockmanship and its benefits to animals. In: Grandin, T. (ed) Improving Animal Welfare: A Practical Approach. Second edition. CABI, Wallingford, UK. pp. 125-138.

Rushen, J., Munksgaard, L., Marnet, P. G. and de Passillé, A. M. (2001): Human contact and the effects of acute stress on cows at milking. Appl. Anim. Behav. Sci. 73, 1-14.

Schmied, C., Boivin, X. and Waiblinger, S. (2008): Stroking different body regions of dairy cows: Effects on avoidance and approach behavior toward humans. J. Dairy Sci. 91, 596-605.

Stafford, K. J. and Mellor, D. J. (2011): Addressing the pain associated with disbudding and dehorning in cattle. Appl. Anim. Behav. Sci. 135, 226-231.

Sutherland, M. A., Rogers, A. R. and Verkerk, G. A. (2012): The effect of temperament and responsiveness towards humans on the behavior, physiology and milk production of multiparous dairy cows in a familiar and novel milking environment. Physiol. Behav. 107, 329-337.

Svennersten-Sjaunja, K. M. and Petterson, G. (2008): Pros and cons of automatic milking in Europe. J. Anim. Sci. 86, Suppl. 1, 37-46.

Tarvainen, M. P. and Niskanen, J. P. (2008): Kubios HRV Version 2.0 User's Guide. Department of Physics, University of Kuopio, Kuopio, Finland.

Task Force of the European Society of Cardiology, North American Society of Pacing and Electrophysiology (1996): Heart rate variability: standards of measurement, physiological interpretation, and clinical use. Circulation 93, 1043-1065.

Waiblinger, S., Menke, C. and Fölsch, D. W. (2003): Influences on the avoidance and approach behaviour of dairy cows towards humans on 35 farms. Appl. Anim. Behav. Sci. 84, 23-39.

Weiss, D., Helmreich, S., Möstl, E., Dzidic, A. and Bruckmaier, R. M. (2004): Coping capacity of dairy cows during the change from conventional to automatic milking. J. Anim. Sci. 82, $563-570$.

Weiss, D., Möstl, E. and Bruckmaier, R. M. (2005): Physiological and behavioural effects of change over from conventional to automatic milking in dairy cows with and without previous experience. Vet. Med. Czech 50, 253-261.

Welfare Quality (2009): Welfare Quality Assessment Protocol for Cattle. Welfare Quality Consortium, Lelystad, The Netherlands.

Windschnurer, I., Schmied, C., Boivin, X. and Waiblinger, S. (2008): Reliability and inter-test relationship of tests for on-farm assessment of dairy cows' relationship to humans. Appl. Anim. Behav. Sci. 114, 37-53. 